\title{
Sediment Transport Dynamics in the Upper Nara Canal Off-taking from Sukkur Barrage of Indus River
}

\author{
Ali Asghar Mahessar \\ Sindh Barrages Improvement Project \\ Sindh Irrigation Department, Karachi, Sindh, Pakistan \\ amahessar@yahoo.com \\ Shafi Muhammad Kori \\ Department of Civil Engineering \\ Mehran University of Engineering and Technology \\ Jamshoro, Pakistan
}

Nisar Ahmed Memon

Faculty of Agricultural Engineering

Sindh Agricultural University

Tandojam, Sindh, Pakistan

\author{
Abdul Latif Qureshi \\ U.S.-Pakistan Centers for Advanced Studies in Water, Mehran \\ University of Engineering and Technology \\ Jamshoro, Pakistan \\ Ghulam Sarwar Faoowui \\ Institute of Water Resources Engineering and Management \\ Mehran University of Engineering and Technology \\ Jamshoro, Pakistan
}

\author{
Ashfaque Ahmed Memon \\ Department of Civil Engineering \\ Mehran University of Engineering and Technology \\ Jamshoro, Pakistan
}

\author{
Khalifa Qasim Leghari \\ Department of Civil Engineering \\ Mehran University of Engineering and Technology \\ Jamshoro, Sindh, Pakistan
}

\begin{abstract}
Sediment material transported by the Indus River has two origins, the catchment and its wetted perimeter, whereas the amount of materials transported from the river itself depends on variables such as the flow type and the sediment load. The annual sediment load transported in the Indus River ranged from 270 to 600 million tons (MT) before the building of dams and barrages. The average sediment load is $0.715 \mathrm{MT} / \mathrm{day}$ or approximately 260 MT/ year after the construction of hydraulic structures. The average particle size, D50, of the bedload is approximately $0.125 \mathrm{~mm}$ at the Sukkur barrage [1]. In this study, research was conducted to evaluate sediment problems in the Nara Canal, take-off from the left pocket of the Sukkur Barrage on the Indus River. The collected data from the left pocket, the bed, and suspended material in upper Nara and its off-taking canals were analyzed to assess sediment transport dynamics of upper Nara canal at various locations and its off-taking canals. The bed material at RD 553+600 shows a minimum size of 0.07 and a maximum of $0.7 \mathrm{~mm}$ with $54 \%$ fine-sand mixed with $46 \%$ medium-sand in 2003. Fine-sand increased to an average of $75 \%$ while medium sand diminished to $25 \%$ at RD $553+600$ in Nara canal and at RD 595+000 in Jamrao complex in 2013. The suspended load with low and high flows during 2012 exhibits that in all the cases the sand proportion was increasing in the Upper Nara canal system flowing to the Jamrao complex. The sediment concentration value indicates that there is the deposition of sand at the upper Nara canal and the Jamrao complex causing a discharge reduction in the Nara Canal system.
\end{abstract}

Keywords-Indus River; Nara canal; sediment transport dynamics; silt deposition; irrigation system

\section{INTRODUCTION}

The canals intake sediments from the rivers and tend to deposit them. Even a very small proportion of sediment if deposited in the irrigation system changes flow behavior [1]. The sediment material transported by the Indus River has two origins: the catchment and its bank and bed. The sediment yield from watershed varies with the size of catchment, the runoff volume, the geology, and the land cover. The amount of sediment originating from the river itself rests on the type of sediment and flow capacity. Indus is a dynamic river which changes behavior both temporally and spatially by varying channel pattern, channel dimension, different morphologies can be found along its length while it frequently floods. It is braided, it has high and low sinuosity, it has meanders etc. The reach of the river, where the Sukkur barrage is located, has also great variability [1]. The sediment transport fluxes of Himalayan Rivers are substantially higher than those of other mountainous regions of the world. If dams and barrages had not been constructed, the three principal rivers of the Indian sub-continent would have annually transported a combined total sediment of 1.2 Giga Tons/year to the coast [2]. The five Himalayan Rivers viz. Brahmaputra, Ganga, Indus, Irrawaddy, and Mekong carry $89 \%$ (1.6 Giga Tons per year) of the total 
annual global flux. Prior to the construction of barrages and dams the annual sediment load ranges from 270 to $600 \mathrm{MT}$ in Indus River [3]. The Indus carries a heavy sediment load that is estimated about 200MT/year in Tarbela and about 330MT/year at Kotri, downstream of the Sukkur barrage. The average annual sediment load in the Indus River at Sukkur was about 360MT during 1902-1960 [4]. Irrigation canals of Indus basin receive high amounts of silt because they off-take directly from Indus river and its tributaries [5].

The types of sediment in the lower Indus range from silt to fine sand, with a decrease estimated in the annual sediment transport at Sukkur and Kotri Barrages. The analyzed characteristic $\mathrm{D}_{90}$ of sediment near Sukkur barrage was found it to be $0.23 \mathrm{~mm}$ [3]. The sediment samples collected in July have been analyzed in order to study the sediment concentration and the size of the materials at different areas of the barrage and the canals. The representative material of the Indus River at Sukkur is very fine sand with a characteristic diameter $D_{50}$ of approximately $0.125 \mathrm{~mm}$. The concentrations of sand are between 200 and 400ppm during high flows presenting some larger peaks, and are almost negligible during low floods [6]. Most of the canal systems on Indus Basin Irrigation System (IBIS) are directly fed from the Indus River and its tributaries which carry heavy sediment particles which settle down in canal beds, hence, create serious operation and maintenance problems. Sediment transport from rivers varies in the canals. Albeit canals and rivers have a similar nature, at the same time there are many variations in the width ratio, the sediment loads, hydrodynamics, etc. [7]. Moreover, the design of the canal system is such that most sediment particles remain suspended and are distributed into the off-taking canals to reach the irrigation fields. Despite this, these particles tend to settle down. Thus frequent canal maintenance and de-siltation is required to keep the canal operational which causes an additional burden on national economy [8].

Sedimentation and erosion of canals cause serious maintenance and operation problems [9]. If the velocity of the flowing water is high, it picks up the particles from the bed of the canal. If the velocity of the flowing water is low, the heaviest sediment particles deposit on the bed consequently $[10,11]$. The bed load generally consists of coarser particles that control the shape, stability, and hydraulic characteristics of the channel [12]. The bed load is accumulated when there is low velocity within stream and heavier grain size sediments get settled. Suspended transport load which is due to lighter grain size material kept in suspension with moving water [13]. Sediment transport is studied from a physical point of view for almost two hundred years but it is not yet fully understood [14]. The canals carry sediment particles for the developing regime and equilibrium condition of the channel. Under this condition, there are not deposition and erosion problems [15]. Nonequilibrium conditions and deposition occur when the sediment concentration is higher than the transport capacity. It also depends upon the morphological characteristics of the river $[16,17]$. In non-uniform flow, the sediment transport capacity keeps changing due to flow parameter differences along the canals. The consequence is the need to modify the sediment concentration in the water flow by unceasing either the deposition or the entrainment on/off the bed of the canal. These adjustment processes occur more or less instantly for bed load and relatively slow for suspended load. The transport mode occurs next to the bed, while it takes time and space to settle down for the suspended load. The time lag needed to adjustment process makes the sediment transport in nonequilibrium condition [18].

This research work has been conducted in order to compute the sediment transport dynamics in the Upper Nara canal and its off-taking canal systems.

\section{RESEARCH METHODOLOY}

\section{A. Study Area}

Sukkur Barrage is located on the Indus River and was commissioned in 1932 to supply water through a network of canals: 4 on the left bank (East and West Kharipur Feeder, Rohri, and Nara) and 3 on the right bank (Dadu, Rice, and North Western). Sukkur Barrage comprises of 66 bays (60ft span each) and is divided in sections: right under-sluices (bays 1-5) to flush the right pocket, weir portion (bays 6-59) and left under-sluice (60-66) to flush the left pocket. Nara canal offtakes from the left bank of the barrage which is located at $27^{\circ} 40^{\prime} 44^{\prime \prime} \mathrm{N}$ latitude and $68^{\circ} 50^{\prime} 42^{\prime \prime} \mathrm{E}$ longitude. Nara is the largest canal in Sindh having a length of $364 \mathrm{~km}$ and its designed capacity is 13,602 cusecs (cubic feet per second). It behaves like a river and irrigates about two million acres of agricultural land. Nara canal at Jamrao complex controls the flows into the lower Nara canal, Jamrao canal, Jamrao twin canal, and Ranto canal. Recently, three fall structures were constructed along the Nara canal to stabilize the flow regime and curb silt deposition. The current study has been carried out in order to find the impact of sediment characteristic dynamics at the upper Nara canal and at the Jamrao complex where the Lower Nara, Jamrao, Twin Jamrao, and Ranto canals off-take.

\section{B. Data Collection}

In order to compute the behavior of sediment transport in the Upper Nara canal, data of sediment transport (bed and suspended load) were collected at locations RD 17+800, $550+000,553+600,576+000,584+000$, and 591+000, Ranto Canal, 5+100 and its off-taking canals including Lower Nara canal, 8+200, Jamrao Canal, 12+000 and Twin Jamrao, 2+100 (Figure 1(b)). The locations from RD $550+000$ to $584+000$ are in the downstream of fall structure in the Upper Nara canal. Data regarding bed and suspended material have been received from the Water and Power Development Authority (WAPDA) and Sindh Irrigation and Drainage Authority (SIDA) [19]. The sediment data for the above two sources have already been reported by SCARPs Monitoring Organization (SMO), in collaboration with the International Sedimentation Research Institute of Pakistan (ISRIP) of WAPDA. The discharge and sediment measurements were carried out at the selected locations during the low flow (April, 2012) and the high flow (July/August, 2012) seasons in the prevailing conditions as the baseline data by SIDA. Subsequently, sediment measurements were repeated during the high flow season (July to September, 2014), at the mentioned locations. 
(a)

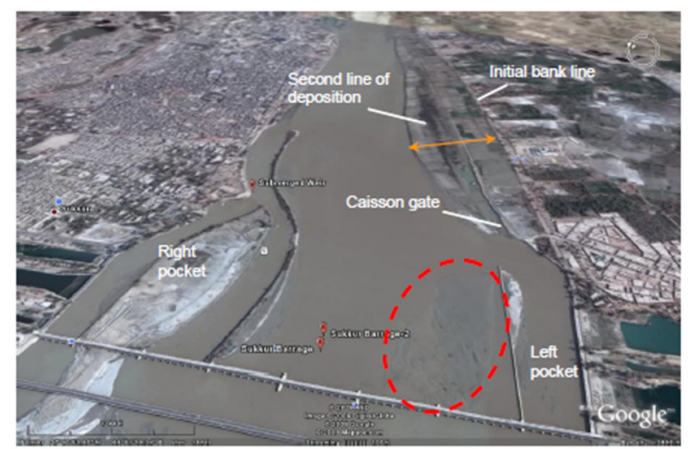

(b)

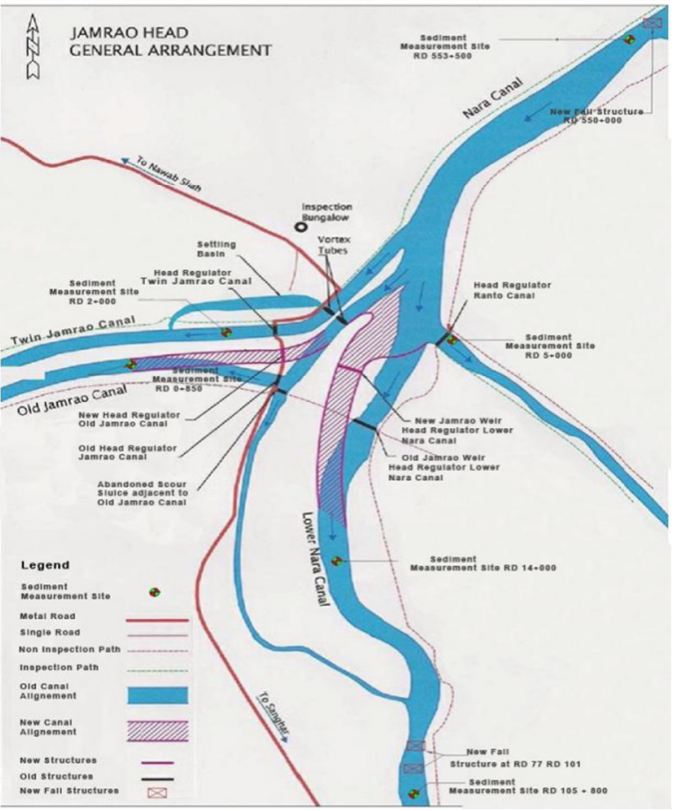

Fig. 1. (a) Upstream of Sukkur barrage (C) 2020 Google, (C) Maxar Technologies), (b) Upper and Lower Nara canal and the Jamrao complex (C) SIDA, Sindh Irrigation Department).

\section{Laboratory Analysis}

The suspended and bed sediment samples were collected during the field measurements and were analyzed for sediment concentration and for particle size gradation while the bed material samples were analyzed for particle size distribution. Sediments coarser than 62 microns were analyzed by Visual Accumulation (VA) / bottom withdrawal tube method / sieve method, while the analysis of finer sediments was carried out with the Pipet method. The concentration of suspended sediment samples was determined with the use of the gravimetric method.

\section{Development of Gradation Curves and Percentile Size}

The gradation curves of the observed bed load samples were developed for assessing the sedimentation bed load in the canal. Seven percentile sizes, $\mathrm{D}_{5}, \mathrm{D}_{16}, \mathrm{D}_{25}, \mathrm{D}_{50}, \mathrm{D}_{75}, \mathrm{D}_{84}$ and $\mathrm{D}_{95}$ were obtained from the gradation curves [20].

\section{E. Transportation Dynamics}

In order to study the transportation dynamics in the study area, the suspended sediment concentration was calculated. Suspended sediment samples along with discharge were taken from various stations of the Nara canal system, viz. the Upper Nara canal at the head reach (RD 17+800), the Upper Nara canal at RD 553+600, the Jamrao canal at RD $12+000$, the Twin Jamrao canal at RD $2+100$, the Lower Nara canal at RD 8+200, and the Ranto canal at RD 5+100.

\section{RESULTS AND DISCUSSION}

\section{A. Grain Size Characteristics of Intaking Canals from the Left and Right Pockets of the Barrage}

The monsoon season lasts from the $1^{\text {st }}$ of July to the $15^{\text {th }}$ of September and causes heavy rain falls in the catchment area of the Indus River. High temperature is maintained which causes snow melting in the glaciers. In the last week of September, the flow in rivers recedes which reduces sediment transport load. Figure 2 shows the sediment samples from the left and right pockets of the intaking canals.

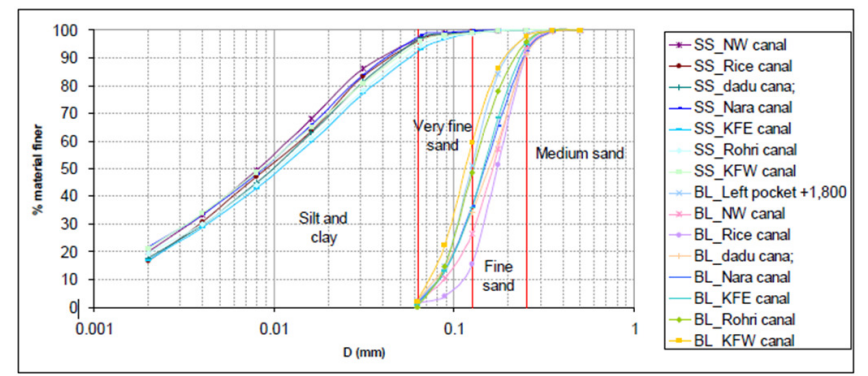

Fig. 2. Grain size distribution. Suspended and bed load material at irrigation canals.

Figure 2 also shows that the suspended load varies from silt and clay to fine sand while the bed load varies from fine sand to medium sand. The $\mathrm{D}_{50}$ of suspended load ranges from 0.008 to $0.01 \mathrm{~mm}$ and that of bed load ranges from 0.125 to 0.15 . The sediment size distribution at the irrigation canals also show that the representative average sizes are approximately the same. It is clear from the plot that the bed samples in the canals correspond to very fine sand. This is the size of material that is depositing in the canals and therefore, it would be desirable to remove as much as possible before entering the canal. Figure2 shows that there is a slight reduction of the percentage of coarser materials (average) that flows into the canals in relation to the one at the entrance of the left and right pockets. When comparing the concentrations of sand at the entrance of the pocket and at the irrigation canals, it can be observed that in general, similar or lower concentrations of sand are measured in the canals although higher values can be observed at particular days. The general trend of sedimentation concentration (ppm) in the left pocket is shown in Figure 3. Concentrations of sand are approximately 200-300ppm during high flows, presenting some lag peaks, whereas they are almost negligible during low flows. Sand is transported as bed load and also in suspension although sediment samples show that silt and clay are the predominant sizes in suspension. Floods during July and August carry the $70 \%$ of the total annual sediment of the river and approximately $80 \%$ of the total amount of sand (material coarser than $0.063 \mathrm{~mm}$ ). 


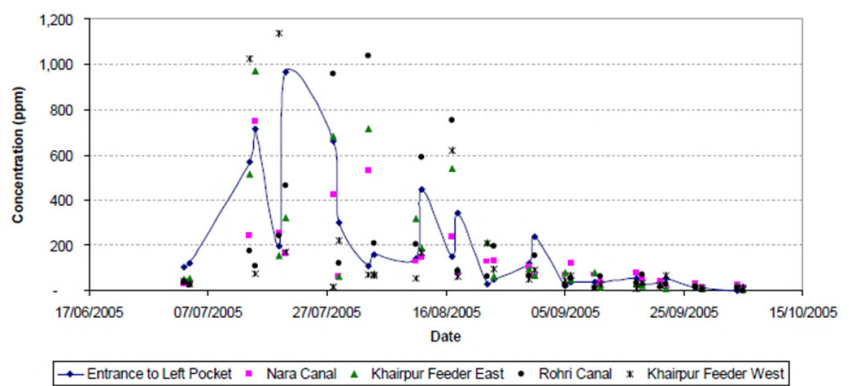

Fig. 3. Concentration of sand at the entrance of the left pocket of the four irrigation canals.

\section{B. Grain Size Characteristics of Nara Canals and its Off- taking Canal System Units}

For determining the grain size characteristics, data regarding bed and suspended load material in the Nara canal system were collected and analyzed. Sieve analysis of the bed load material (sampled in 2003 and 2013) was carried out. The average sediment size (D) has been computed for each bed material. These percentile sizes along with the calculated average sediment size are exhibited in Table I.

TABLE I. PASSING PERCENTILE SIZES AND AVERAGE SEDIMENT SIZE (D) AT VARIOUS LOCATIONS (RD) OF THE UPPER NARA CANAL

\begin{tabular}{|c|c|c|c|c|c|c|c|c|c|}
\hline Date & RD & $\mathbf{D}_{\mathbf{5}}$ & $\mathbf{D}_{\mathbf{1 6}}$ & $\mathbf{D}_{\mathbf{2 5}}$ & $\mathbf{D}_{\mathbf{5 0}}$ & $\mathbf{D}_{\mathbf{7 5}}$ & $\mathbf{D}_{\mathbf{8 4}}$ & $\mathbf{D}_{\mathbf{9 5}}$ & $\mathbf{D}$ \\
\hline $\begin{array}{c}\text { Mar 18, } \\
\mathbf{2 0 0 3}\end{array}$ & $553+600$ & 0.08 & 0.09 & 0.095 & 0.105 & 0.12 & 0.13 & 0.17 & 0.101 \\
\hline $\begin{array}{c}\text { Apr 30, } \\
\mathbf{2 0 0 3}\end{array}$ & $553+600$ & 0.13 & 0.16 & 0.16 & 0.20 & 0.25 & 0.28 & 0.35 & 0.216 \\
\hline $\begin{array}{c}\text { May 18, } \\
\mathbf{2 0 0 3}\end{array}$ & $553+600$ & 0.13 & 0.17 & 0.19 & 0.22 & 0.27 & 0.30 & 0.35 & 0.234 \\
\hline $\begin{array}{c}\text { Jun 14, } \\
\mathbf{2 0 0 3}\end{array}$ & $553+600$ & 0.13 & 0.145 & 0.80 & 0.21 & 0.26 & 0.29 & 0.35 & 0.314 \\
\hline $\begin{array}{c}\text { Sep 12, } \\
\mathbf{2 0 1 3}\end{array}$ & $576+000$ & 0.115 & 0.13 & 0.14 & 0.16 & 0.21 & 0.22 & 0.28 & 0.163 \\
\hline $\begin{array}{c}\text { Sep 18, } \\
\mathbf{2 0 1 3}\end{array}$ & $576+000$ & 0.11 & 0.13 & 0.135 & 0.16 & 0.20 & 0.23 & 0.27 & 0.161 \\
\hline $\begin{array}{c}\text { Sep 24, } \\
\mathbf{2 0 1 3}\end{array}$ & $591+000$ & 0.09 & 0.11 & 0.12 & 0.15 & 0.18 & 0.20 & 0.23 & 0.154 \\
\hline $\begin{array}{c}\text { Sep 25, } \\
\mathbf{2 0 1 3}\end{array}$ & $584+000$ & 0.075 & 0.09 & 0.10 & 0.14 & 0.20 & 0.22 & 0.25 & 0.143 \\
\hline $\begin{array}{c}\text { Sep 28, } \\
\mathbf{2 0 1 3}\end{array}$ & $576+000$ & 0.12 & 0.13 & 0.14 & 0.17 & 0.22 & 0.24 & 0.3 & 0.171 \\
\hline
\end{tabular}

The values of $\mathrm{D}_{50}$ for the September 2013 vary from 0.14 to $0.17 \mathrm{~mm}$. The analyzed results of the collected samples on 18 March and 14 June 2003 show canal flow variation of the delivered Indus River water. The results on Table I clearly indicate that all bed load materials have size above $0.163 \mathrm{~mm}$, i.e. there is no silt proportion, the sand deposited is only of fine or medium size. Usually the percentage of medium sand is less than the one of fine sand. From Table II it is concluded that there is no silt proportion being deposited in the bed of the canal. It is either fine or median grained sand. The deposited material also indicates that the proportion of sediment size (fine or medium in \%) is being transported in the canal depending on its discharge and velocity, e.g. in March the velocity is sluggish, thus $97 \%$ of fine material gives up, and during the last week of April, it is $39 \%$, with an average of $40 \%$. The fine grand material percentage increases again during the September of 2013 readings. Their average comes to about $75 \%$.
TABLE II. SEDIMENT SIZE AND MATERIAL TYPE FOR THE BED LOAD MATERIAL OF THE UPPER NARA CANAL

\begin{tabular}{|c|c|c|c|c|c|}
\hline \multirow[b]{2}{*}{ S. No } & \multirow[b]{2}{*}{ RD } & \multirow[b]{2}{*}{ Date } & \multirow{2}{*}{$\begin{array}{l}\text { Sediment } \\
\text { size }\end{array}$} & \multicolumn{2}{|c|}{ Type of passing material } \\
\hline & & & & $\begin{array}{c}\text { Fine sand } \\
(\%)\end{array}$ & $\begin{array}{l}\text { Medium } \\
\text { sand (\%) }\end{array}$ \\
\hline 1 & $553+600$ & Mar 18, 2003 & $0.08-0.35$ & 97 & 3 \\
\hline 2 & $553+600$ & Apr 30, 2003 & $0.12-0.50$ & 39 & 61 \\
\hline 3 & $553+600$ & May 18,2003 & $0.12-0.50$ & 32 & 68 \\
\hline 4 & $553+600$ & Jun 14,2003 & $0.12-0.7$ & 49 & 51 \\
\hline 5 & $576+000$ & Sep 12, 2013 & $0.115-0.35$ & 72 & 28 \\
\hline 6 & $576+000$ & Sep 18, 2013 & $0.11-0.35$ & 73 & 27 \\
\hline 7 & $591+000$ & Sep 24, 2013 & $0.08-0.35$ & 85 & 15 \\
\hline 8 & $584+000$ & Sep 25, 2013 & $0.07-0.35$ & 78 & 22 \\
\hline 9 & $576+000$ & Sep 28, 2013 & $0.11-0.5$ & 66 & 34 \\
\hline
\end{tabular}

This also indicates that no silt particles were found at the bed, they remained in suspension. Rivers originating from the Himalaya origin belt region are characterized by the predominance of fine sand and very fine sand [21-24]. On the contrary, the rivers draining from the northern Indian Craton region bring much coarser sediments and are characterized by the high content of coarse- and medium-grained sand. As the Indus alluvial plain originates from the Himalaya region it carries finer bed load sediments. Figure 4 shows the distribution of sand, silt, and clay from the upper Nara canal at RD $17+800$ to the Upper Nara canal at RD 553+600 during the low flow session of 2012. The Figure clearly indicates that during the high flow of 2012, the sediment concentration is high irrespective of the location/RD. It also indicates that during the high discharge monsoon period, silt particles are at the highest level. However, the sand proportion is more at RD $553+600$ than at RD $17+800$.

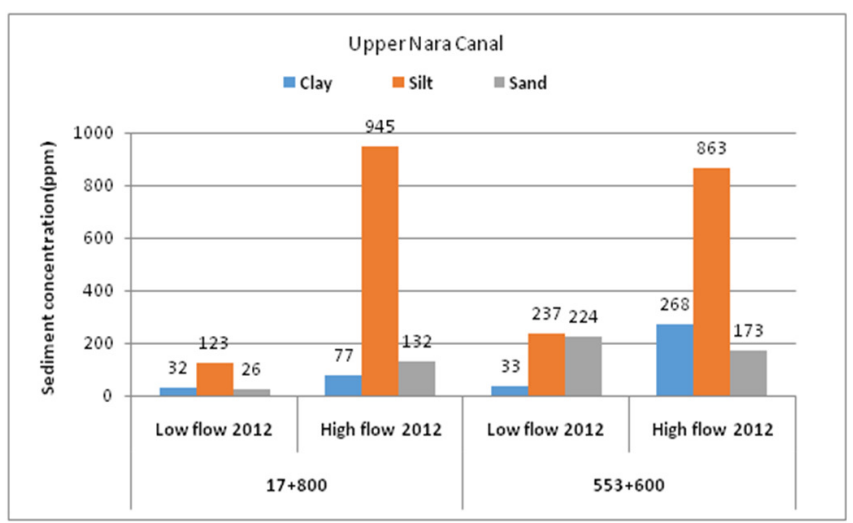

Fig. 4. Sediment concentration (ppm) in the Upper Nara canal for low and high flow, 2012.

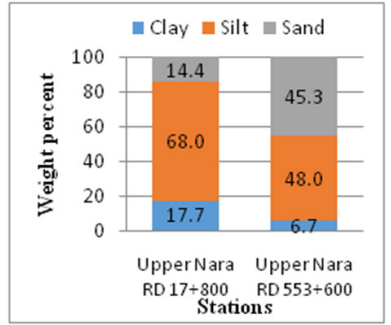

(a)

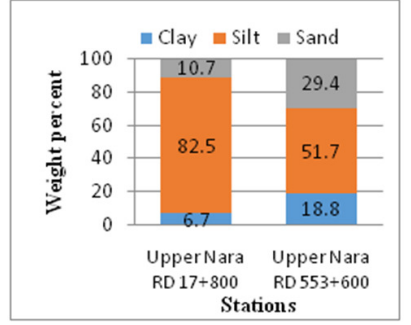

(b)
Fig. 5. Sediment proportions in the Upper Nara canal during 2012: (a) low flow, (b) high flow. 
It can be seen in Figure 5 that the sand proportion from the upper Nara canal at RD $17+800$ to the RD 553+600 increased whereas silt and clay proportions decreased. This indicates that deposition occurred during the low flow. In Figure 5, it can be seen that a substantial amount of sand and silt eroded from the Upper Nara canal between RD $17+800$ and RD 553+600 during the high flow of 2012. It is a fact that if the flow of the water is high, erosion from bed and scouring from the sides of an alluvial canal like Nara will be more. It has also been observed that the severity of erosion also depends on the turbulence of flow in the canal. On the contrary, when there is low flow, the suspended sediment particles are being deposited on the canal bed.

\section{Sediment Transport from Jamrao Complex to Lower Nara and Off-taking Canals}

During the high flows of 2012, the suspended load was distributed from the Upper Nara canal at RD 17+800 and RD $553+800$ and from Jamrao complex to its off-taking canals, i.e. the Jamrao canal at RD $12+000$, the Twin Jamrao canal at RD $2+100$, and the Ranto canal at RD 5+100 including the Lower Nara canal at RD 8+200 (Figures 6-7).

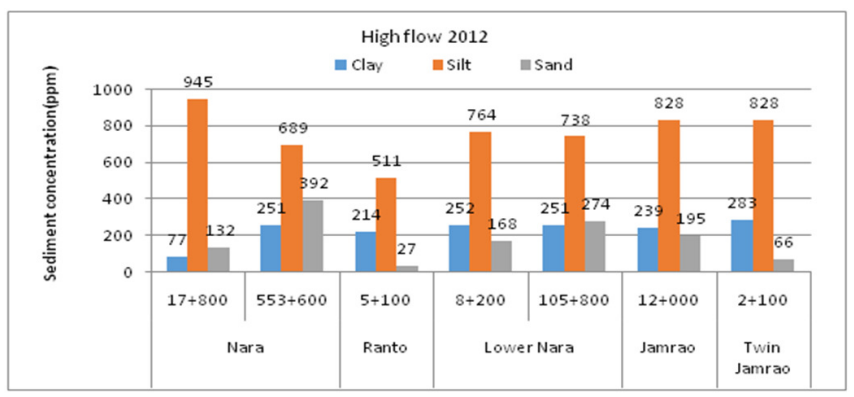

Fig. 6. Sediment transport from the Upper Nara canal to its off-taking canals at the Jamrao complex during the high flow, 2012.

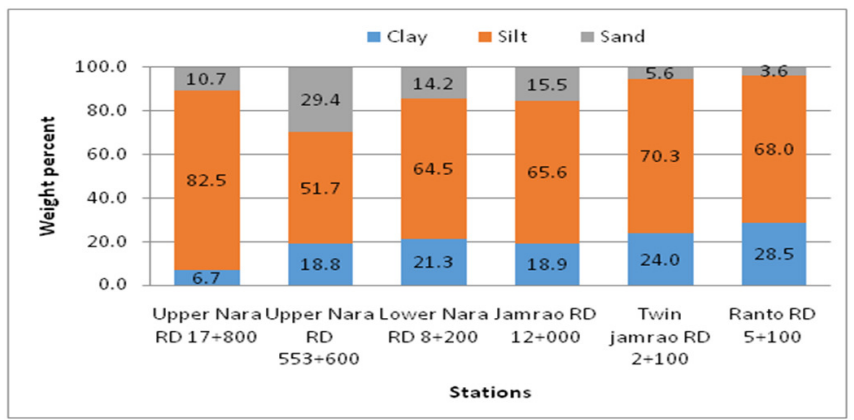

Fig. 7. Sediment transport percentage from the Upper Nara canal to its off-taking canals at the Jamrao complex during the high flow, 2012.

Figure 7 shows that the increase in the weight of sand, silt, and clay from the Upper Nara canal at RD 553+600 is $29.4 \%$, $51.7 \%$, and $18.8 \%$ respectively. This means that there is sand erosion/scouring (i.e. from $77 \mathrm{ppm}$ to $251 \mathrm{ppm}$ ), whereas silt particles from the upper Nara canal at RD $17+800$ to RD $553+600$ are reduced (from $945 \mathrm{ppm}$ to $689 \mathrm{ppm}$ ). Figures 6 and 7 show that from the Jamrao complex to the off-taking canals, the distribution of sand, silt, and clay is $15.5 \%, 65.6 \%$, and $18.9 \%$ respectively. In Twin Jamrao there is a small amount of sand, i.e. $5.6 \%$, silt is increased to $70.3 \%$, and clay is about $24 \%$. In Ranto canal, at RD 5+100 the percentage of sand is only $3.6 \%$, silt is $68 \%$, and clay is $28.5 \%$. In the Lower Nara canal at RD $8+200$, the sand proportion is increased. The percentages of sand, silt, and clay are about $14.2 \%, 64.5 \%$, and $21.3 \%$ respectively. Sediment transport from the Upper Nara canal to Lower Nara and the off-taking canals at Jamrao Complex is shown in Figure 8, which shows the distribution of sand, silt, and clay concentrations from the Upper Nara canal at $\mathrm{RD} 553+600$ to its off-taking canals, i.e. the Jamrao canal at RD 12+000 and the Twin Jamrao canal at RD 2+100 including the Lower Nara canal at RD 8+200 during the low flow season of 2012. During the low flow of 2012, sand particles of the Upper Nara canal are either deposited in the Jamrao complex or are carried out to Jamrao and Lower Nara canals, whereas only less than $30 \%$ is transported into the Twin Jamrao canal as shown in Figure 8. Sand, silt, and clay proportions are shown in Figure 9. Sand and silt are not equally distributed from the Jamrao complex to their off-taking canals. In the Jamrao canal at $\mathrm{RD} 12+000$, the sand proportion is $27.3 \%$, the silt proportion is $64.9 \%$ and the clay proportion is $8 \%$, whereas in the Twin Jamrao canal at RD $2+100$, the sand proportion is about $36.5 \%$, silt is $53.5 \%$, and clay is $10 \%$.

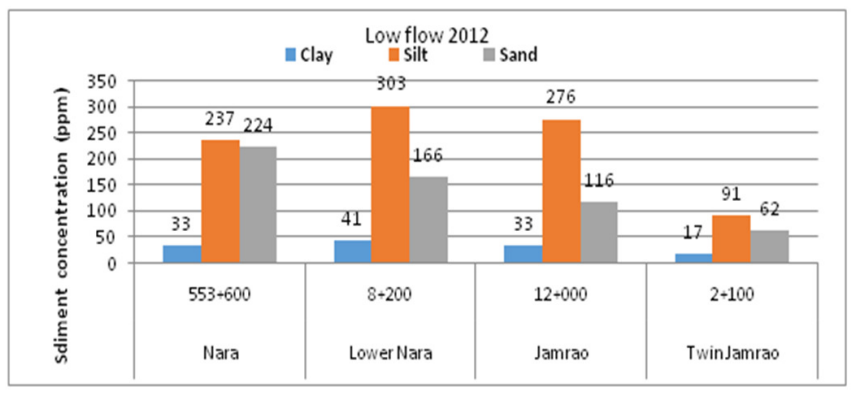

Fig. 8. Sediment transport percentage from the Upper Nara canal to its off-taking canals at Jamrao complex during the low flow, 2012.

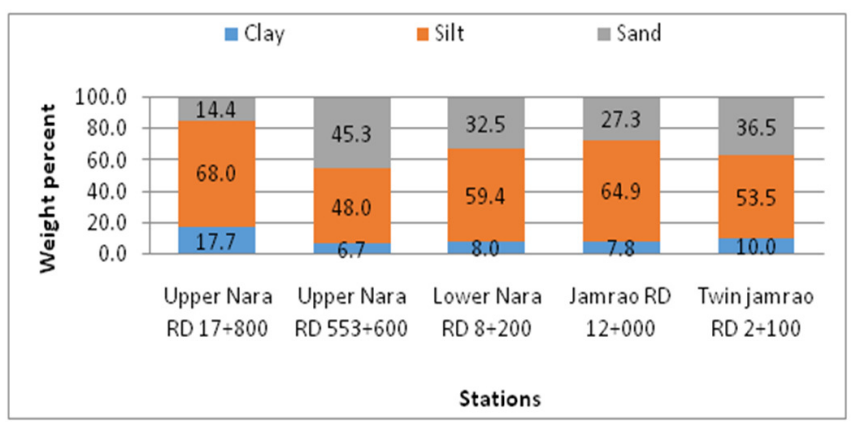

Fig. 9. Sediment transport from the Upper Nara Canal to its off-taking canals at the Jamrao complex during the low flow, 2012.

From Figure 9, it observed that the amount of weight percent of sand, silt and clay particles at Lower Nara canal RD $8+200$ is $32.5,59.4$ and 8.0 respectively. It is observed that clay proportion is almost equally distributed from the Jamrao complex to its off-taking canals. This Figure shows that at the Upper Nara canal RD 17+800 sand, silt and clay proportions are $14.13 \%, 68 \%$ and $17.7 \%$ respectively whereas at the Upper Nara canal at RD 553+600, the weight percent of sand, silt and 
clay is about to $45.3,48$ and 6.7 respectively, which means they are not equally distributed to RD $17+800$ and $553+600$. Table IV demonstrates that the ratio of high to low flow is about 2 in Nara (Upper and Lower) and about 1.5 for Jamrao and Jamrao Twin canals. However, the concentration ratio during the high to low flow is more than 2, it even reaches 6 to 7 times in Upper Nara at RD $17+800$ and in Twin Jamrao at RD $2+100$.

TABLE III. 2012 HIGH TO LOW FLOW COMPARISON OF DISCHARGE AND CONCENTRATION FATIOS

\begin{tabular}{|c|c|c|c|c|c|c|c|}
\hline \multirow{2}{*}{ Canal } & \multirow{2}{*}{ Location } & \multicolumn{2}{|c|}{$\begin{array}{c}\text { Observed } \\
\text { discharge }\end{array}$} & \multirow{2}{*}{ Ratio } & \multicolumn{2}{|c|}{$\begin{array}{c}\text { Observed } \\
\text { sediment } \\
\text { concentration }\end{array}$} & \multirow{2}{*}{ Ratio } \\
\cline { 3 - 7 } & & $\begin{array}{c}\text { Low } \\
\text { flow }\end{array}$ & $\begin{array}{c}\text { High } \\
\text { flow }\end{array}$ & & $\begin{array}{c}\text { Low } \\
\text { flow }\end{array}$ & $\begin{array}{c}\text { High } \\
\text { flow }\end{array}$ & \\
\hline $\begin{array}{c}\text { Upper } \\
\text { Nara }\end{array}$ & $17+800$ & 8210 & 15909 & 1.94 & 181 & 1154 & 6.38 \\
\hline $\begin{array}{c}\text { Upper } \\
\text { Nara }\end{array}$ & $553+600$ & 6841 & 14257 & 2.08 & 494 & 1332 & 2.70 \\
\hline Ranto & & closed & 934 & N. A. & ---- & 752 & N. A. \\
\hline $\begin{array}{c}\text { Lower } \\
\text { Nara }\end{array}$ & $08+200$ & 2882 & 6043 & 2.09 & 510 & 1184 & 2.32 \\
\hline Jamrao & $12+000$ & 1395 & 2122 & 1.52 & 425 & 1262 & 2.97 \\
\hline $\begin{array}{c}\text { Twin } \\
\text { Jamrao }\end{array}$ & $02+100$ & 2680 & 4204 & 1.57 & 170 & 1177 & 6.92 \\
\hline
\end{tabular}

During the high flood, more sediment concentration was moving at RD $17+800$ of the Nara canal and in Twin Jamrao at RD $2+100$. At RD $17+800$ of the Nara canal, most of sandy particles were transported from the Indus River and were deposited in the Upper Nara canal system up to the Jamrao complex, keeping only silt particles in suspension. At RD $2+100$ of the Twin Jamrao, the concentration ratio from high to low flow shows a higher value, because of less sediment inflow during the low flow season as its concentration is only $170 \mathrm{ppm}$. The deposition and erosion process of natural canals like Nara depend up on the interaction between channel flow and sediment transport (i.e. suspended load) and bed forms as has been described in [19]. In alluvial channels, the flow regime has significant effects on channel morphology and sediment load transportation. During the monsoon, high discharge flowing in the canal controls the sediment transport dynamics.

\section{CONCLUSIONS}

The general trend in the left pocket is that sands have approximately concentration of 200-300ppm during the high flows and almost negligible during the low flows. Sand is transported as bed load and also in suspension although sediment samples show that silt and clay are the predominant particles in suspension. Floods during July and August carry the $70 \%$ of the total annual sediment of the river and approximately the $80 \%$ of the total amount of sand. The observed bed load material, during the year 2003 at RD $553+600$ shows sizes from $0.07 \mathrm{~mm}$ to $0.7 \mathrm{~mm}$. It is concluded from the analysis that the bed load material consists of $54 \%$ fine sand mixed with $46 \%$ medium sand. It is also concluded that the sediment proportion of fine sand in the bed load has been increased in 2013 to an average of $75 \%$ keeping the medium sand to $25 \%$ at various RDs in Nara canal and the Jamrao complex. This concludes that a substantial amount of fine sand has been deposited in this reach.
The suspended load observed during the low and high flows of 2012 indicates that in all cases the sand proportion was increased in the Upper Nara canal system. The sediment concentration value clearly indicates that there is a deposition of sand at the Jamrao complex, which has also been observed from the geo-morphological cross-sections. The analysis of the suspended sediment concentration concludes that the amount of sand deposited in the Upper Nara canal is not shared by the old Jamrao and Jamrao Twin canals. From the morphological observations/cross-sections, it is observed that the dredging of bed material and the construction of fall structures have reduced the erosion and the transport of sediment towards the off-taking canals. Hence, it is concluded that there is a considerable impact of the development works conducted for the water sector improvement.

\section{ACKNOWLEDGMENT}

The authors are thankful to the Sindh Irrigation and Drainage Authority (SIDA), the Mehran University of Engineering and Technology, Jamshoro, Sindh, Pakistan and the Water and Power Development Authority (WAPDA).

\section{REFERENCES}

[1] H. R. Wallingford, "Sukkur Barrage Morphological Studies," EX 6847 R2, Sep. 2012

[2] J. D. Milliman and J. P. M. Syvitski, "Geomorphic/Tectonic Control of Sediment Discharge to the Ocean: The Importance of Small Mountainous Rivers," The Journal of Geology, vol. 100, no. 5, pp. 525544, Sep. 1992, https://doi.org/10.1086/629606.

[3] J. F. Shroder Jr, "Morphohlogy and Dynamics of the Indus River: Implications for the Mohen Jo Daro Site," in Himalaya to the Sea: Geology, Geomorphology and the Quaternary, Taylor \& Francis Group, 2002, https://doi.org/10.4324/9780203414637-26.

[4] A. Ali, Indus Basin Floods: Mechanisms, Impacts, and Management. ADB, 2013.

[5] C. M. White and G. I. Taylor, "The equilibrium of grains on the bed of a stream," Proceedings of the Royal Society of London. Series A. Mathematical and Physical Sciences, vol. 174, no. 958, pp. 322-338, Feb. 1940, https://doi.org/10.1098/rspa.1940.0023.

[6] Sindh Barrages Improvement Project - Sukkur Barrage Rehabilitation and Modernization. Sindh, Pakistan: Government of Sindh, Pakistan Irrigation Department, 2017.

[7] R. Galappatti, "A depth integrated model for suspended transport," Communications on Hydraulics, vol. 1983, no. 7, 1983.

[8] S. Munir, Role of Sediment Transport in Operation and Maintenance of Supply and Demand Based Irrigation Canals: Application to Machai Maira Branch Canals, 1st edition. Leiden: Routledge, 2011.

[9] A. Agrawal, "Numerical Modelling of Sediment Flow in Tala Desilting Chamber," M.S. thesis, Norwegian University of Science and Technology, Trondheim, Norway, 2005.

[10] S. Haun and N. R. B. Olsen, "Three-dimensional numerical modelling of the flushing process of the Kali Gandaki hydropower reservoir," Lakes \& Reservoirs: Science, Policy and Management for Sustainable Use, vol. 17 , no. 1 , pp. $25-33,2012$, https://doi.org/10.1111/j.14401770.2012.00491.x.

[11] D. Lysne, B. Glover, H. Stole, and E. Tesaker, Hydraulic Design. Norwegian University of Science and Technology, 2003.

[12] W. H. Graf, Fluvial Hydraulics: Flow and Transport Processes in Channels of Simple Geometry. New York, NY, USA: Wiley, 1998.

[13] S. S. Ginsberg and S. Aliotta, "Sediment Transport Circulation Pattern through Mesotidal Channels System," Sediment Transport, Apr. 2011, https://doi.org/10.5772/15687.

[14] P. Frey and M. Church, "How river beds move," Science, vol. 325, no. 5947, pp. 1509-1510, 2009, https://doi.org/10.1126/science.1178516. 
[15] A. Vabre, "Methodologies for design, operation and maintenance of irrigation canals subject to sediment problems application to Pakistan," IIMI, Pakistan National Program, ISRIP, CEMAGREF, Lahore, Pakistan, 1996.

[16] J. M. Turowski, D. Rickenmann, and S. J. Dadson, "The partitioning of the total sediment load of a river into suspended load and bedload," presented at the EGU General Assembly 2009, Vienna, Austria, Apr. 2009.

[17] X. Wang, Q. Yang, W. Lu, and X. Wang, "Effects of Bed Load Movement on Mean Flow Characteristics in Mobile Gravel Beds," Water Resources Management, vol. 25, no. 11, Jun. 2011, Art. no. 2781, https://doi.org/10.1007/s1 1269-011-9838-6.

[18] K. P. Paudel, Role of Sediment in the Design and Management of Irrigation Canals: UNESCO-IHE PhD Thesis, 1st ed. CRC Press, 2010.

[19] Water Sector Improvement Project (WSIP), (2015), "Impact on sediment transport due to developments in Nara canal", Monitoring and Evaluation Report, Sindh Irrigation and Drainage Authority.

[20] F. G. Sarwar, "Sediment Characteristics and Transportation Dynamics of Upper Nara Canal," M.S. thesis, Mehran University of Engineering and Technology, Jamshoro, Sindh, Pakistan, 2016.

[21] S. Singh, S. Rai, and S. Krishnaswami, "Sr and Nd isotopes in river sediments from the Ganga Basin: Sediment provenance and spatial variability in physical erosion," Journal of Geophysical Research-Earth Surface, vol. 113, no. F3, Jul. 2008, Art. no. F03006, https://doi.org/10.1029/2007JF000909.

[22] A. A. Mahessar, A. L. Qureshi, A. N. Laghari, S. Qureshi, S. F. Shah, and F. A. Shaikh, "Impact of Hairdin, Miro Khan and Shahdad Kot Drainage on Hamal Dhand, Sindh," Engineering, Technology \& Applied Science Research, vol. 8, no. 6, pp. 3652-3656, Dec. 2018, https://doi.org/10.48084/etasr.2389.

[23] A. A. Mahessar, K. Ansari, G. M. Arain, S. M. Kori, S. Qureshi, and A. L. Qureshi, "Impact of Right Bank Outfall Drain-I (RBOD-I) / Main Nara Valley Drain (MNVD) on Manchar Lake, Sindh, Pakistan," Engineering, Technology \& Applied Science Research, vol. 9, no. 6, pp. 5074-5079, Dec. 2019, https://doi.org/10.48084/etasr.3219. 